\title{
Testosterone Synthesis in Patients with 17ß-Hydroxysteroid Dehydrogenase 3 Deficiency
}

\author{
R. Werner ${ }^{a} \quad$ A. Kulle ${ }^{c} \quad$ I. Sommerfeld ${ }^{a} \quad$ F.G. Riepe S. Wudy $^{d} \quad$ M.F. Hartmann ${ }^{d}$ \\ H. Merz ${ }^{b} \quad$ U. Döhnert ${ }^{a} \quad$ S. Bertelloni ${ }^{\text {e }} \quad$ P.-M. Holterhus ${ }^{c} \quad$ O. Hiort ${ }^{\mathrm{a}, \mathrm{b}}$ \\ ${ }^{a}$ Division of Pediatric Endocrinology, Department of Pediatric and Adolescent Medicine, and ${ }^{b}$ Department of \\ Pathology, University of Lübeck, Lübeck, 'Division of Pediatric Endocrinology, Department of Pediatrics, Christian \\ Albrechts University, Kiel, and d Division of Pediatric Endocrinology, Department of Pediatrics, Justus Liebig

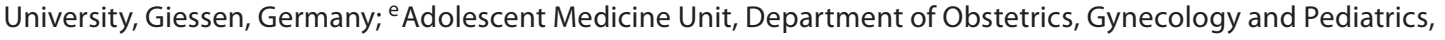 \\ Santa Chiara University Hospital, Pisa, Italy
}

\section{Key Words}

Androgen biosynthesis - Disorders of sex development * $17 \beta$-hydroxysteroid dehydrogenase 3 deficiency

\section{Abstract}

$17 \beta$-hydroxysteroid dehydrogenase 3 (17ß-HSD 3) deficien$c y$ is a rare cause of $46, X Y$ disorders of sex development (DSD). At puberty, these patients experience a surge of androstenedione and also testosterone, leading to substantial virilization. The origin of testosterone synthesis in these patients remains elusive. We investigated the expression of the isoenzyme AKR1C3 (17 $\beta$-HSD 5) in the testis and patient-derived genital skin fibroblasts (GSF) as well as the ability of GSF to synthesize testosterone. Supernatants of GSF cultures and serum samples of one patient before and after gonadectomy were analyzed by liquid and gas chromatography/mass spectrometry. The androgenic potential of GSF-derived supernatants was also assessed by androgen receptor-mediated transactivation of a reporter gene in transiently transfected Chinese hamster ovary cells. Although AKR1C3 is expressed both in the testes and in GSF, androstenedione is rapidly metabolized and is not synthesized to testosterone.
The transactivation potential of GSF supernatants towards the androgen receptor is declining within $48 \mathrm{~h}$. However, under testis-equivalent androstenedione concentration, testosterone can be synthesized in 17 $\beta$-HSD 3-negative GSF. After gonadectomy, both androstenedione and testosterone decline rapidly in vivo. In 17 $\beta$-HSD 3 deficiency, relevant amounts of testosterone are synthesized most probably through AKR1C3 in the testis and not peripherally in GSF.

Copyright $\odot 2012$ S. Karger AG, Basel

$17 \beta$-hydroxysteroid dehydrogenase 3 (17 $\beta$-HSD 3) deficiency is a rare form of 46, XY disorders of sex development with an incidence of approximately 1:140,000 newborns [Boehmer et al., 1999]. It is caused by mutations in the HSD17B3 gene and inherited in an autosomal-recessive fashion. $17 \beta$-HSD 3 is the most important enzyme for testicular conversion of androstenedione to testosterone. Due to the lack of testosterone during male sex differentiation, 46,XY children with 17 $\beta$-HSD 3 deficiency are often born with almost female-appearing external genitalia despite histologically normal testes [Bertelloni et al., 2009]. The development of androgen-dependent

\section{KARGER}

Fax +4161306 1234

E-Mail karger@karger.ch

www.karger.com
(C) 2012 S. Karger AG, Basel

$1661-5425 / 12 / 0064-0161 \$ 38.00 / 0$

Accessible online at:

www.karger.com/sxd
Olaf Hiort, MD

Division of Pediatric Endocrinology and Diabetes

Department of Pediatric and Adolescent Medicine, University of Lübeck

Ratzeburger Allee 160, DE-23538 Lübeck (Germany)

Tel. +49 451500 2191, E-Mail Hiort@ paedia.ukl.mu-luebeck.de 
structures like prostate, seminal vesicles and epididymis is variable.

At the time of puberty, these patients experience a massive surge of androstenedione and also measurable serum values for testosterone in the lower male reference range [Andersson et al., 1996; Twesten et al., 2000; Lee et al., 2007]. Clinically, this leads to dramatic virilization, and sometimes changes of gender role of the affected adolescents from female to male have been reported [Rosler, 2006]. At this time, it is unknown if accumulation of androstenedione itself or other pathways of testosterone synthesis not accounted for during embryogenesis and surpassing the dysfunctional $17 \beta-H S D 3$ contribute to this pubertal virilization. Furthermore, the origin of pubertal testosterone synthesis in 17ß-HSD 3 deficiency has not been elucidated yet [Rosler, 2006; Bertelloni et al., 2009].

In humans, at least 12 different isoenzymes of the $17 \beta$ HSD fulfill specific roles in sex steroid metabolism by catalyzing the conversion of low-activity 17-ketosteroids, such as androstenedione and estrone to their more potent $17 \beta$-hydroxysteroid forms, testosterone or estradiol and reverse [Moeller and Adamski, 2009]. The expression pattern of all $17 \beta$-HSD isoenzymes including the type 3 varies among cell types and tissues as well as during age, and thus, other $17 \beta$ isoenzymes may be capable to replace defective 17 $\beta$-HSD 3 functions during adolescence [Moeller and Adamski, 2009]. Especially AKR1C3 (17 $\beta$ HSD 5) has been proposed to contribute to testosterone synthesis in skin and hair follicles [Labrie et al., 2000a, b]. Furthermore, this enzyme is highly expressed in genital skin of both scrotal and foreskin origin, and its mRNA content has been reported to increase during adolescence [Hoppe et al., 2006]. AKR1C3 expression has also been documented in Leydig cells of normal male testis biopsies [Pelletier et al., 1999]. Moreover, it was recently shown that this enzyme contributes significantly to adrenal testosterone formation especially in women [Nakamura et al., 2009].

To this date, there is neither published information on gonadal AKR1C3 expression in patients with 17 $\beta$-HSD 3 deficiency nor of its potential functional relevance. In contrast, the surge of androstenedione during puberty in patients with $17 \beta$-HSD 3 deficiency might lead to testosterone conversion directly in the genital structures to induce virilization.

To determine whether a possible extratesticular testosterone synthesis contributes to the phenotype of pubertal virilization in $17 \beta-H S D$ deficiency, we investigated 4 unrelated patients bearing the same disruptive muta- tion in the HSD17B3 gene (c. $277+4 \mathrm{~A}>\mathrm{T}$, described as $325+4 \mathrm{~A}>\mathrm{T}$ [Boehmer et al., 1999]). In one patient, we were able to study serum samples before and shortly after gonadectomy as well as the expression of AKR1C3 in the testes by immunohistochemistry. Additionally, steroid metabolism in genital skin fibroblasts (GSF) from the other 3 patients with $17 \beta$-HSD 3 deficiency was studied and compared to normal male control samples. Furthermore, we analyzed the expression of AKR1C3 in the GSF and also determined whether the supernatant of androstenedione-treated cell cultures changed the transactivation of an androgen-inducible reporter gene in androgen receptor (AR)-transfected cell lines over time.

\section{Subjects and Methods}

Subjects

Four patients with proved $17 \beta-$ HSD 3 deficiency were studied. All 4 patients had a 46,XY karyotype and were raised in the female sex. The age at the time of investigation was 10 years (ARD111), 18.5 years (ARD1318), 13.3 years (ARD1373), and 16.1 years (ARD1853). Patient ARD111 was still prepubertal and was gonadectomized to prevent unwanted virilization. In the other 3 patients, the diagnosis was only made because of virilization at puberty. While patient ARD1318 had only slight signs of virilization with acne and hirsutism, in the latter 2 patients (ARD1373 and ARD1853), strong signs of virilization included clitoromegaly. $17 \beta-H S D 3$ deficiency was investigated by molecular genetic analysis of the HSD17B3 gene with sequencing of all exons including intron-exon boundaries. All patients were found to carry the previously described splice-site mutation c. $277+4 \mathrm{~A}>\mathrm{T}$ in a homozygous fashion [Boehmer et al., 1999; Twesten et al., 2000]. This mutation leads to aberrant splicing and a nonfunctional protein [Boehmer et al., 1999].

Genital skin was obtained at the time of gonadectomy in patients ARD111, ARD1318 and ARD1373 after the diagnosis was made. In patient ARD1853, genital skin was not removed and cultured when gonadectomy was performed. For controls, we selected GSF of scrotal origin from 3 normal males aged 9 (Sc12), 13 $(\mathrm{Sc} 3)$ and $34(\mathrm{Sc} 9)$ years who had been operated for medical reasons. All patients or controls or, in the case of minors, parents gave informed consent to further studies, and the investigations were approved by the Ethics Committee of the University of Lübeck (Nr. 01-066).

\section{Cell Culture of Genital Fibroblasts}

Cells from the labioscrotal folds of the patients and of the scrotum of the controls were obtained at surgery and cultured to the 5 th to 8 th passage, then frozen and stored until further use. After that, cells were maintained in $5 \% \mathrm{CO}_{2}$ at $37^{\circ} \mathrm{C}$ in Dulbecco's minimal essential medium with the nutrient mix F-12 (Sigma, Taufkirchen, Germany) supplemented with 10\% charcoalstripped fetal calf serum (PAA Laboratories $\mathrm{GmbH}$, Coelbe, Germany), penicillin (100 U/ ml) and streptomycin $(100 \mu \mathrm{g} / \mathrm{ml})$ (Sig$\mathrm{ma})$. Cells were grown to $90 \%$ confluency in $175-\mathrm{cm}^{2}$ flasks, trypsinized and transferred to 6 -well plates $\left(2 \times 10^{5}\right.$ cells per well $)$ and 
grown to $90 \%$ confluency. Firstly, cells were incubated with 10 $\mathrm{nmol} / \mathrm{l}$ androstenedione and harvested immediately (time point $0 \mathrm{~h}$ ) or after $48 \mathrm{~h}$ or $96 \mathrm{~h}$ incubation at $37^{\circ} \mathrm{C}, 5 \% \mathrm{CO}_{2}$. Secondly, we incubated patient GSF with $700 \mathrm{nmol} / \mathrm{l}$ androstenedione and measured the concentration of testosterone accordingly in the culture medium at time point 0 and after 48 and $96 \mathrm{~h}$.

\section{RNA Preparation}

RNA was isolated using the RNeasy mini kit (Qiagen, Hilden, Germany) according the instructions of the manufacturer. RNA quantity and quality were analyzed on a RNA 6000 Nano Chip using a 2100 Bioanalyzer (Agilent Technologies, Waldbronn, Germany).

\section{$R T-P C R$}

One $\mu \mathrm{g}$ of total RNA was reverse transcribed in a $20 \mu \mathrm{l}$ reaction using Superscript II reverse transcriptase (Invitrogen, Karlsruhe, Germany) and random primers. Subsequently the cDNA was diluted 1:10 with nuclease-free water and analyzed by realtime PCR on a light cycler II instrument (Roche).

Real-time assays were performed using the Light Cycler DNA Master SYBR Green Kit (Roche Applied Science, Mannheim, Germany). Assays for AKR1C3 and porphobilinogen deaminase were performed as described previously [Hoppe et al., 2006]. Specificity of the signals and absence of primer dimers were controlled by melting curve analysis and gel electrophoresis of products. Relative amounts of respective mRNA were estimated using the Relative Quantification Software (Roche Applied Science), and porphobilinogen deaminase as a housekeeping gene.

\section{Liquid Chromatography-Mass Spectrometry}

Liquid chromatography-mass spectrometry was used for targeted determination of androstenedione, testosterone and dihydrotestosterone. All tandem mass spectrometry experiments were performed with a Waters Acquity coupled to a Waters Quattro Premier/Xe after solid-phase extraction of steroids from plasma or cell culture supernatants as described previously [Kulle et al., 2010].

\section{Gas Chromatography-Mass Spectrometry}

Gas chromatography-mass spectrometry was used for nontargeted determination of steroids in cell culture media. In brief, steroids were extracted from cell culture supernatants by solidphase extraction and derivatized to methyloxime-trimethylsilyl ethers [Wudy and Hartmann, 2004]. Gas chromatography-mass spectrometry analysis was carried out on an Agilent 6890 series GC coupled to an Agilent 5973N MSD operated in full scan mode. Ion extraction from total ion chromatograms was used to search for metabolites of interest.

\section{Transient Transfection Assays (Bioassay for AR-Activating} Substances)

Transient transfections were preformed in Chinese hamster ovary $(\mathrm{CHO})$ cells, which were maintained in $5 \% \mathrm{CO}_{2}$ at $37^{\circ} \mathrm{C}$ in Dulbecco's minimal essential medium with the nutrient mix F-12 (Sigma) supplemented with $10 \%$ charcoal-stripped fetal calf serum (PAA Laboratories $\mathrm{GmbH})$, penicillin (100 U/ml), and streptomycin $(100 \mu \mathrm{g} / \mathrm{ml})$ (Sigma). Cells were transfected in 24-well plates using $200 \mathrm{ng}(\mathrm{ARE})_{2}$ TATA luciferase reporter plasmid (a generous gift from Dr. G. Jenster, Rotterdam, The Netherlands),
$30 \mathrm{ng}$ of the AR expression plasmid pSVAR0 (kindly provided by Dr. A. Brinkmann, Rotterdam, The Netherlands), 5 ng of a constitutive Renilla luciferase expression plasmid phRG-TK and 0.5 $\mu l$ Fugene HD transfection reagent (Roche Applied Science) per well according to instructions of the manufacturer. Five hours post transfection $\mathrm{CHO}$ cells were incubated for $18 \mathrm{~h}$ with cell culture supernatants from GSF diluted 1:5 with fresh medium. This assay serves as a highly sensitive bioassay for AR-activating substances by activation of an androgen-responsive reporter gene. Transfection efficiencies were normalized using the dual luciferase assay kit (Promega Corp., Madison, Wisc., USA). All transfections were performed in triplicate and at least 3 independent experiments were performed using GSF supernatants from 3 independent wells of each time point of the GSF incubation experiments. For means of comparison of experiments performed at different days, reporter gene induction due to AR and 1:5 diluted supernatant harvested from the scrotum control (SC) 3 cells at time point 0 (final concentration $2 \mathrm{nmol} / \mathrm{l}$ androstenedione) was set $100 \%$. All other induction values obtained in the same experiment were expressed relative to this value.

\section{Immunoblotting}

For protein analysis, cells were incubated in 6-well plates. At indicated time points medium supernatants were collected and frozen at $-70^{\circ} \mathrm{C}$ for hormone measurements. Cells were washed twice with PBS and harvested by adding $500 \mu \mathrm{l}$ of lysis buffer A (1\% Triton-X 100, 0.5\% Deo, 0.08\% SDS, 40 mmol/l Tris pH 7.4, $1 \mathrm{mmol} / \mathrm{l}$ EDTA, $10 \%$ glycerol, $1 \mathrm{mmol} / \mathrm{l} \mathrm{DTT}, 0.5 \mathrm{mmol} / 1 \mathrm{baci}-$ tracin, and $0.6 \mathrm{mmol} / \mathrm{l} \mathrm{PMSF}$ ). The cells were incubated on ice on a shaker for further $5 \mathrm{~min}$, then transferred to a shredder column (Qiashredder, Qiagen), and cellular debris was pelleted by centrifugation for $10 \mathrm{~min}$ at $14,000 \mathrm{~g}$. Protein concentration was estimated according to Bradford using the BioRad Protein Assay (BioRad Richmond, Calif., USA). Samples were separated by SDSPAGE and transferred onto nitrocellulose membranes. Membranes were blocked using 5\% non-fat skim milk in PBS/Tween 20. AKR1C3 was detected with a goat anti-AKR1C3 antibody (NB-100-1940, Novus, Littleton, Colo., USA) diluted 1:5,000, and actin was detected with a rabbit anti-actin antibody (\#2066, Sigma-Aldrich, Steinheim, Germany) diluted 1:1,000. The respective horseradish peroxidase-conjugated secondary antibodies (polyclonal rabbit anti-goat immunglobulins/HRP, \#P0449, Dako, Hamburg, Germany; goat anti-rabbit IgG-peroxidase, \#A6154, Sigma-Aldrich) were diluted 1:2,000-1:4,000, and signals were detected applying the Western Lightning Chemiluminescent Reagent Plus (Perkin Elmer, Boston, Mass., USA) and Hyperfilm ECL (GE Healthcare, Freiburg, Germany).

\section{Immunohistochemistry}

After gonadectomy, the testis was fixed in $4 \%$ paraformaldehyde and embedded in paraffin. Sections were immunostained with goat anti-AKR1C3 antibody (NB-100-1940, Novus) diluted 1:160. A mouse anti-goat antibody diluted 1:50 was used as a secondary antibody. To reduce nonspecific background due to endogenous peroxidase, the slides were treated with hydrogen peroxide. Bound antibodies were visualized using Bright vision+poly-HRP-Anti Ms/Rb/Rt IgG (Immunologic, Duiven, The Netherlands) and DAB as a substrate. The slides were counterstained with hematoxylin. 
Fig. 1. Immunoblot of AKR1C3 from cultured GSF after incubation with $10 \mathrm{nmol} / \mathrm{l}$ androstenedione for 0,48 and $96 \mathrm{~h}$. Control GSF (Sc3, 9 and 12), patients' GSF (ARD111, 1318, 1378).

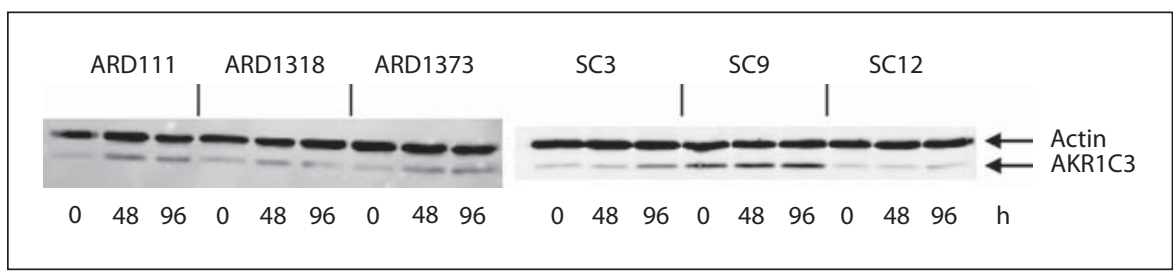

\section{Results}

\section{Expression of AKR1C3 in Genital Skin Fibroblasts}

To evaluate whether the AKR1C3 (17 $\beta$-HSD 5) isoenzyme can contribute to an extratesticular testosterone synthesis in GSFs and subsequent virilization we analyzed the RNA accumulation of AKR1C3 transcripts from 3 normal men (SC) and 3 patients (ARD) with $17 \beta$ HSD type 3 deficiency in cell culture before $(0 \mathrm{~h})$ and after incubation with $10 \mathrm{nmol} / \mathrm{l}$ androstenedione for 48 or $96 \mathrm{~h}$ by RT-PCR from 2 independent incubations each.

In all GSF cultures, accumulation of AKR1C3 mRNA could easily be detected with crossing point values between 21 and 24 cycles using 10 ng of total RNA as a template. Nevertheless, a high variability in AKR1C3 RNA accumulation was seen between cultures (data not shown).

To confirm that these mRNAs are translated into protein, we analyzed all cultures by immunoblotting. Expression of AKR1C3 could be demonstrated in all fibroblast cultures before and after incubation with $10 \mathrm{nmol} / \mathrm{l}$ androstenedione (fig. 1).

\section{Hormone Determinations - Low-Dose \\ Androstenedione}

To determine the ability of GSFs to synthesize testosterone, GSF cultures of the patients ARD111, 1318 and 1373 and the controls SC 3, 9 and 12 were incubated with $10 \mathrm{nmol} / \mathrm{l}$ androstenedione, and androstenedione as well as testosterone concentrations of the cell supernatants were measured by liquid chromatography-mass spectrometry at time point 0 and after 48 and $96 \mathrm{~h}$. We found a decrease of androstenedione to $30 \%$ of the initial value in the first $48 \mathrm{~h}$. After $96 \mathrm{~h}$, the concentration of androstenedione was at the detection limit of $0.1 \mathrm{nmol} / \mathrm{l}$ (fig. 2). On the other hand, testosterone did not show an increase at that time. Testosterone was found at the lower detection limit of $0.1 \mathrm{nmol} / \mathrm{l}$ in all cell lines for the whole incubation time (data not shown). There was no significant difference between the control cell lines and the patient cell lines. To verify that testosterone was not metabolized to dihydrostestosterone, we analyzed the supernatant for

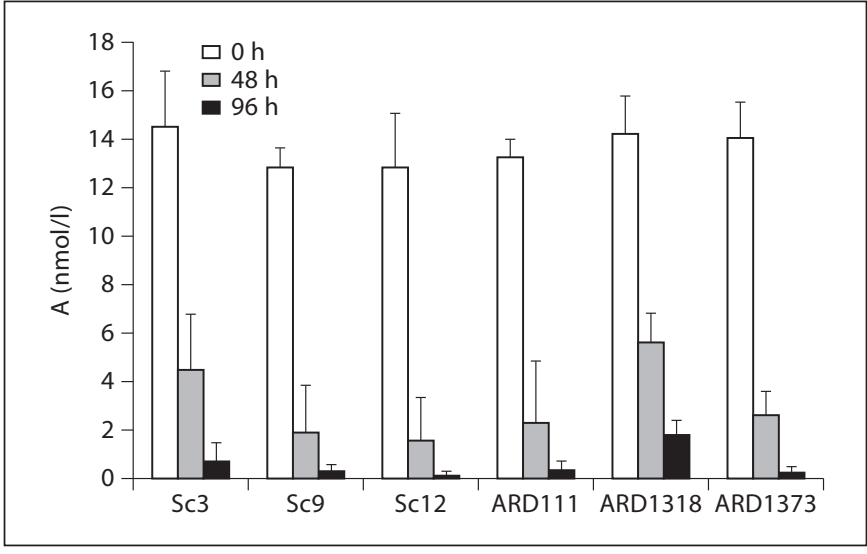

Fig. 2. Androstenedione concentrations in $\mathrm{nmol} / \mathrm{l}$ in the cell culture medium of control (Sc3, 9 and 12) and the patients' GSF (ARD111, 1318, 1378) after medium change containing $10 \mathrm{nmol} / \mathrm{l}$ androstenedione $(0 \mathrm{~h})$ and after 48 and $96 \mathrm{~h}$ of incubation.

dihydrostestosterone. The concentration of dihydrostestosterone in the whole cell lines was at the detection limit of $0.1 \mathrm{nmol} / 1$ (data not shown).

Employing gas chromatography-mass spectrometry, after $96 \mathrm{~h}$ incubation using ion extraction from total ion chromatograms, we were unable to detect all possible isomers of $5 \alpha$ - or $5 \beta$-androstanedioles in the specimens analyzed. Likewise, no traces of 4 -androstenedione, testosterone or $5 \alpha$-dihydrotestosterone were found.

\section{Hormone Determinations - High-Dose Androstenedione}

We elucidated whether under high substrate pressure testosterone synthesis could be observed in $17 \beta$-HSD 3-negative GSF. We incubated patient GSF with 700 $\mathrm{nmol} / \mathrm{l}$ androstenedione and measured the concentration of testosterone in the culture medium at time point 0 and after 48 and $96 \mathrm{~h}$. After 4 days, concentrations between 15 and $20 \mathrm{nmol} / \mathrm{l}$ testosterone could be measured in the GSF supernatants, indicating that these cells are able to convert androstenedione to testosterone at high substrate 


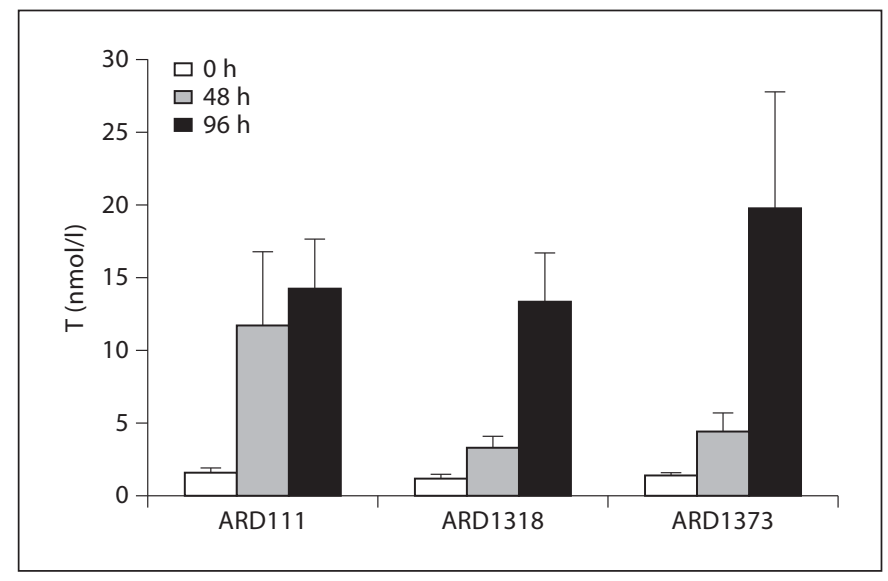

Fig. 3. Testosterone synthesis in 17 $\beta$-HSD 3-deficient GSF. After incubation with high-dose androstenedione (700 nmol/l) GSF of the 3 patients were able to convert androstenedione into testosterone. Each bar represents the average testosterone concentration in the medium supernatant (5 independent incubation wells per time point). Error bars $=$ SD.

concentrations (fig. 3). At time point 0 , concentrations of $1-1.5 \mathrm{nmol} / \mathrm{l}$ testosterone were measured, which might be a contamination $(\approx 0.2 \%)$ of the $700 \mathrm{nmol} / \mathrm{l}$ androstenedione solution.

\section{Androgenic Potential of Cell Culture Supernatants}

The lack of known androstenedione metabolites in the culture supernatants, despite a decline of androstenedione levels to $30 \%$ after $48 \mathrm{~h}$ and to the detection limits after $96 \mathrm{~h}$, led us to extend our search for unknown ligands that might efficaciously activate AR. Therefore, we analyzed the androgenic potential of diluted cell culture supernatants through their ability to activate the AR and induce an androgen-responsive reporter gene in transiently transfected $\mathrm{CHO}$ cells. All supernatants from the 6 different GSF showed a decline of the androgenic potential during time (fig. 4), consistent with the decline of androstenedione (fig. 2) and the concentration response curve of androstenedione at the (ARE) $)_{2}$-TATA promoter in $\mathrm{CHO}$ cells (fig. 5). Without addition of hormone, no basal firefly luciferase expression could be detected.

\section{Expression of AKR1C3 in the Testis}

We analyzed the expression of AKR1C3 in the testis of patient ARD1853 by immunohistochemical staining using an antibody against the c-terminal peptide of human AKR1C3 (CFASHPNYPYSDEY). As illustrated in figure 6 , AKR1C3 is highly expressed in the cytoplasm and nu-

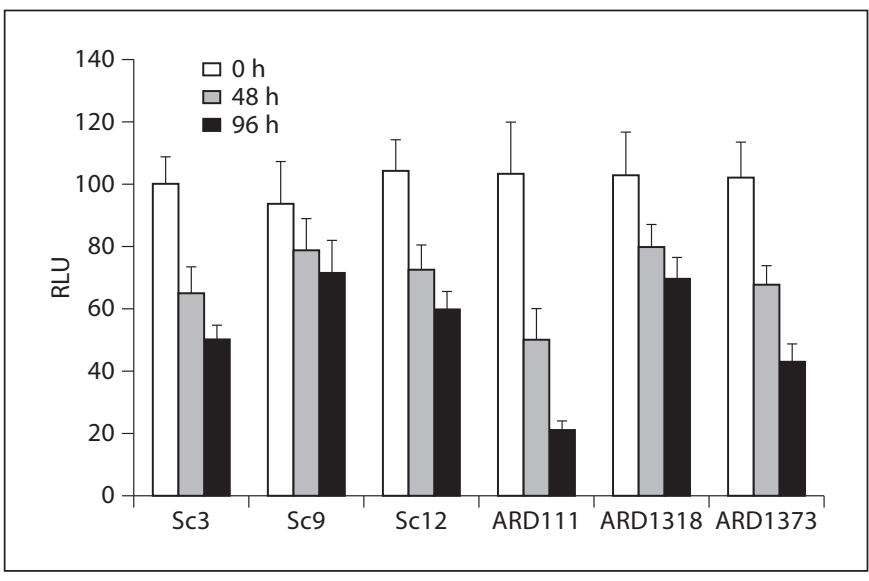

Fig. 4. Decreasing androgenic potential of androstenedionespiked supernatants from GSFs over time. CHO cells were transiently transfected with the androgen-responsive reporter plasmid (ARE) $)_{2}$-TATA-Luc, the androgen receptor expression construct PSVAR0 and the constitutive renilla luciferase construct phRG-TK. Five hours post transfection, $\mathrm{CHO}$ cells were incubated for $18 \mathrm{~h}$ with supernatants from indicated cell lines and time points diluted with charcoal-stripped medium 1:5. Each bar represents the average of 3 independent transfection experiments performed in triplicates. Error bars $=S D$. RLU = Relative luciferase units.

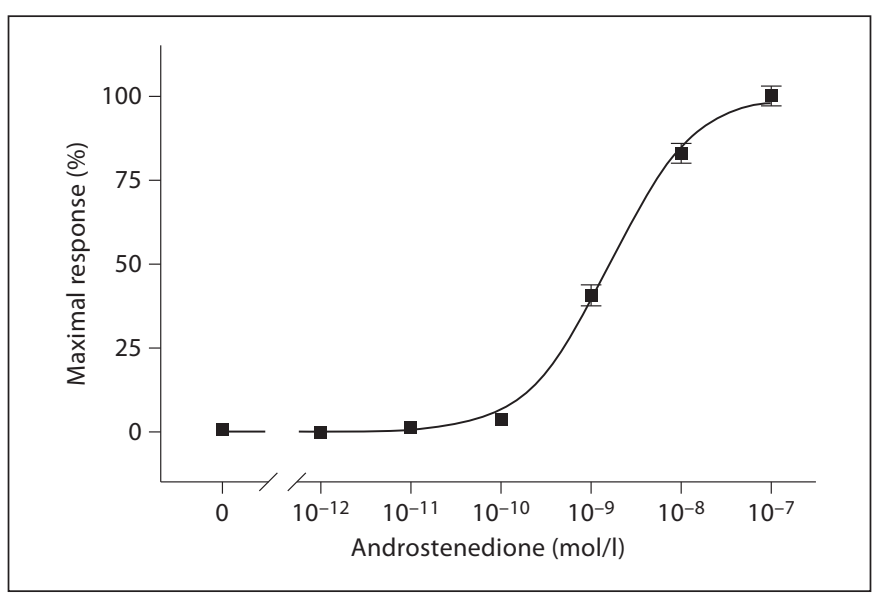

Fig. 5. Androstenedione concentration-response curve at the $(\mathrm{ARE})_{2}$-TATA promoter in $\mathrm{CHO}$ cells. $\mathrm{EC}_{50}: 1.6 \times 10^{-9} \mathrm{~mol} / \mathrm{l}$ $\left(95 \%\right.$ confidence interval $1.38 \times 10^{-9}$ to $\left.1.87 \times 10^{-9}\right)$.

clei of Leydig cells and in peritubular cells in patient ARD1853 as well as in a normal control. Germ cells and Sertoli cells showed only a weak staining. In the testis of patient ARD1853, seminiferous tubuli showed a Sertoli cell only pattern, without presence of germ cells. 

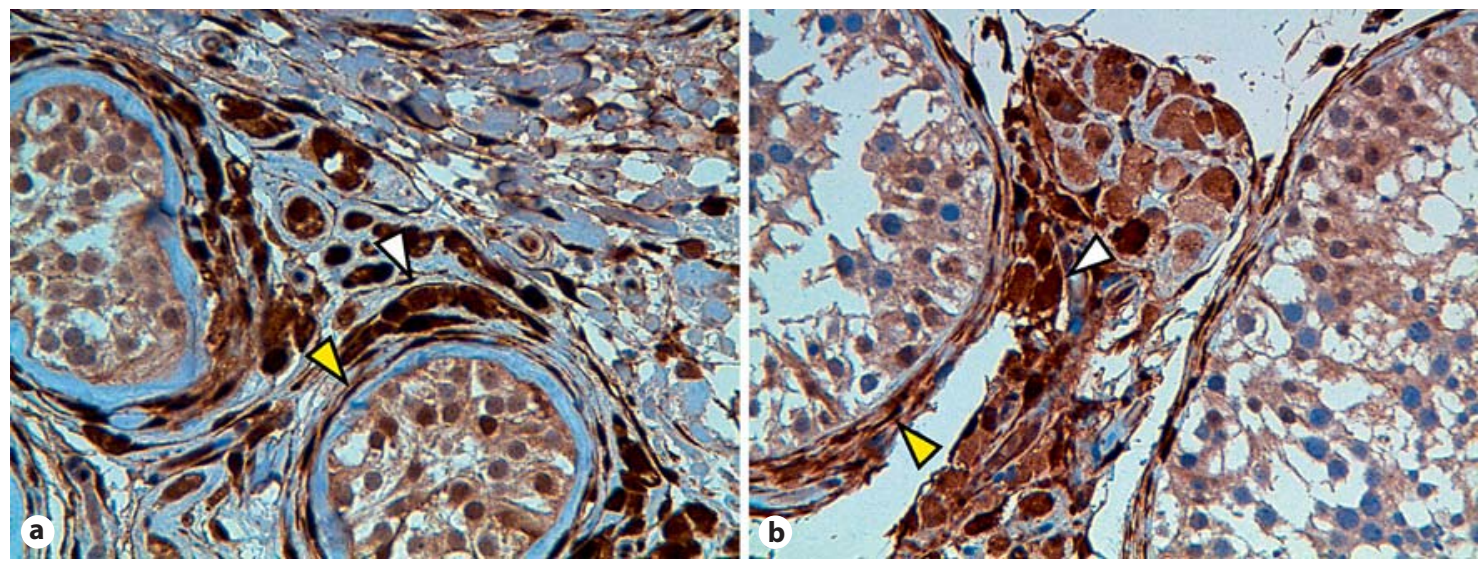

Fig. 6. Immunohistochemical localization of AKR1C3 in the testis of patient ARD1853 (a) and a normal control (b). Leydig cells (white arrowheads) and peritubular cells (yellow arrowheads) show a strong expression of AKR1C3.

\section{Discussion}

In this work, we performed studies on the source of pubertal testosterone synthesis in patients with $17 \beta-H S D$ 3 deficiency. Although the patients were not related, they all harbor the deleterious splice site mutation c. $277+4$ $\mathrm{A}>\mathrm{T}$ in the HSD17B3 gene, which has previously been shown to result in aberrant splicing and a completely defective 17 $\beta$-HSD 3 enzyme [Boehmer et al., 1999]. Hence, if these patients have relevant amounts of testosterone and the concurrent clinical effects at puberty, testosterone synthesis must be through alternative pathways. It has been postulated that elevated amounts of androstenedione are converted to testosterone in peripheral tissues [Andersson et al., 1996; Boehmer et al., 1999; Luu-The, 2001; Hoppe et al., 2007]. In our investigations of patient ARD1853, we could demonstrate that both testosterone and androstenedione took a sharp drop within $48 \mathrm{~h}$ after gonadectomy (table 1). However, androstenedione declined to $20 \%$ of initial value and was still higher than the age-related reference value for females $(2.79-6.63 \mathrm{nmol} / \mathrm{l})$, while testosterone declined to $2.5 \%$ of initial value. Thus, once the source of androstenedione is removed, also testosterone is not synthesized anymore. This is most likely due to the fact that most of this conversion takes place in the testes, as we have shown that the Leydig cells of the removed testes of patient ARD1853 express the isoenzyme AKR1C3 considerably (fig. 6).

We then investigated the capability of GSF available from patients ARD111, ARD1318 and ARD1373 to synthesize androgenic steroids from androstenedione in order to determine whether these cells might contribute
Table 1. Endocrine values of patient ARD1853 before and $48 \mathrm{~h}$ after gonadectomy with respective reference values

\begin{tabular}{lcl}
\hline & & $\begin{array}{l}\text { Normal reference } \\
\text { values (males) }\end{array}$ \\
\hline Before gonadectomy & & \\
$\quad$ LH, IU/l & 14.99 & $0.4-7.0$ \\
Testosterone, nmol/1 & 3.91 & $3.5-10.7$ \\
Androstenedione, nmol/1 & 103.33 & $1.4-17.3$ \\
48 h after gonadectomy & & \\
LH, IU/l & 17.48 & NA \\
Testosterone, nmol/1 & 0.1 & NA \\
Androstenedione, nmol/1 & 18.87 & NA \\
\hline NA = Not applicable. & & \\
\hline
\end{tabular}

considerably to the testosterone synthesis in the absence of $17 \beta-H S D$ 3. GSF have been used for numerous experiments in androgen metabolism and action of patients with disorders of sex development. They are derived from genital skin, a well-characterized androgen-dependent target tissue and they express both $17 \beta-H S D ~ 3$ and $17 \beta$ HSD 5 [Hoppe et al. 2006]. However, cell cultures may not reflect the in-vivo situation in a complex tissue of different cell types like skin. To obtain the most uniform conditions for our experiments, we have used cell cultures from similar passages, all bearing the same molecular abnormality in the HSD17B3 gene leading to a disruption of $17 \beta-H S D 3$ expression. Control tissues were from complementary sites of normal males of similar age and were studied in similar passages. Our study demonstrates 
that these cells do not produce testosterone from androstenedione under conditions that would apply to physiological serum levels of these hormones, nor that they synthesize relevant potent androgens for induction of androgenization as shown by a highly sensitive reporter gene assay (fig. 4). This excludes also a relevant conversion of androstenedione to DHT by $5 \alpha$-reductases in these cells [Samson et al., 2010].

Testosterone biosynthesis can be facilitated from different precursors, namely through the $\Delta 4$ pathway from androstenedione or through the $\Delta 5$ pathway from androstenediol, the latter with the possibility to bypass the $17 \beta$ HSD 3 enzyme [Luu-The et al., 2008]. In males, the $\Delta 4$ pathway via androstenedione is the main source of testosterone synthesis in Leydig cells where 17ß-HSD 3 is highly expressed. However, Labrie et al. [2000a] state that only about $50 \%$ of the testosterone is derived directly from the testis and proposes that in the prostate and other androgen target tissues AKR1C3 is capable to synthesize large amounts of testosterone. If an extratesticular origin of testosterone synthesis via AKR1C3 would take place in genital skin, both an endocrine and a direct intracrine action were to be postulated to explain the massive virilization effects on the phallus and labioscrotal folds. We have shown by RT-PCR and Western blotting that AKR1C3 is expressed in the GSF of patients and controls. This would point to a possible source of testosterone synthesis in these cells. Earlier, 17ß-HSD activity was demonstrated in human skin extracts, leading to conversion from androstenedione to testosterone [Martel et al., 1992]. However, in all our cultures no relevant testosterone synthesis was documented employing physiological androstenedione concentrations available to these cells. From our experiments, we would hypothesize that no relevant amounts of testosterone are produced in GSF despite expression of AKR1C3. Also, other androgenic steroids were not found. We have used a traditional reporter gene assay with the wild-type androgen receptor for incubation with the androstenedione-spiked cell culture supernatants and saw declining androgen receptor activation (fig. 4). With this experimental setting, any relevant potent androgenic steroid would have been detectable in its action. Although androstenedione is slowly metabolized with relevant proportions still present after $48 \mathrm{~h}$ (fig. 2), we could not detect relevant amounts of any known metabolite. This would point to a metabolism of androstenedione not through the known pathways via $17 \beta$-dehydroxylation or aromatization. From these findings, we would propose that in GSFs, a metabolism or degradation of androstenedione occurs through a process so far not elucidated.
We have demonstrated earlier [Holterhus et al., 2002] and again in the experiments presented here that androstenedione has a highly relevant transactivation potential on the androgen receptor in vitro. 17 $\beta$-HSD 3-deficient patients have been reported to have elevated androstenedione serum levels compared to normal males or females (table 1). We have shown in the experiments here that under supraphysiological concentrations of androstenedione $(700 \mathrm{nmol} / \mathrm{l})$, cells expressing AKR1C3, but not 17ßHSD 3, are capable of relevant testosterone synthesis. Concentrations in this range $(500 \mathrm{nmol} / \mathrm{l})$ were also used in the in vitro experiments analyzing human skin extracts with the proof of relevant testosterone synthesis [Martel et al., 1992]. In 17 $\beta$-HSD 3-deficient patients, extremely elevated androstenedione concentrations were measured in the vena spermatica, reaching up to $1.5 \mu \mathrm{mol} / \mathrm{l}$, resembling a 15-25-fold increase to normal men [Andersson et al., 1996]. We have detected a strong immunostaining of AKR1C3 in the cytoplasm and nuclei of Leydig cells and peritubular cells and weak staining in Sertoli and germ cells. A similar immunoreactivity of AKR1C3 in adult testis was observed previously with 2 other AKR1C3 specific antibodies [Pelletier et al., 1999; Azzarello et al., 2008], confirming its expression in the testis. As the testes of the patient also express relevant amounts of AKR1C3 (fig. 6), it may well be that the Leydig cells of these patients are a significant source of testosterone synthesis under androstenedione substrate pressure. Hence, pubertal virilization in $17 \beta$-HSD 3 deficiency could most likely be a combination of both, high androstenedione levels and testicular testosterone synthesis via AKR1C3.

We conclude that the testosterone synthesis in patients with 17ß-HSD 3 deficiency and their progressive virilization at the time of puberty is still not completely understood; however, a major source of testosterone are the testes. Most likely, relevant conversion from androstenedione to testosterone via AKR1C3 does not occur in peripheral GSF, but might well take place in cells with highly elevated androstenedione exposure as the testicular Leydig cells.

\section{Acknowledgements}

The authors wish to thank D. Struve, S. Olin, S. Stein, and S. Struve for excellent technical assistance. This work was financed primarily by the German Ministry for Research and Education (BMBF grant 01GM0625 to O.H., R.W. and P.M.H.). In addition, the research leading to these results has received funding from the European Community's Seventh Framework Programme (FP7/2007-2013) under grant agreement 201444 (to R.W., O.H., P.M.H., F.G.R.). This work was part of the medical thesis from I.S.

Sex Dev 2012;6:161-168 


\section{References}

-Andersson S, Geissler WM, Wu L, Davis DL, Grumbach MM, et al: Molecular genetics and pathophysiology of 17 beta-hydroxysteroid dehydrogenase 3 deficiency. J Clin Endocrinol Metab 81:130-136 (1996).

-Azzarello J, Fung KM, Lin HK: Tissue distribution of human AKR1C3 and rat homolog in the adult genitourinary system. J Histochem Cytochem 56:853-861 (2008).

Bertelloni S, Dati E, Hiort O: Diagnosis of $17 \beta$ hydroxysteroid dehydrogenase deficiency. Expert Rev Endocrinol Metab 4:53-65 (2009).

- Boehmer AL, Brinkmann AO, Sandkuijl LA, Halley DJ, Niermeijer MF, et al: 17Beta-hydroxysteroid dehydrogenase-3 deficiency: diagnosis, phenotypic variability, population genetics, and worldwide distribution of ancient and de novo mutations. J Clin Endocrinol Metab 84:4713-4721 (1999).

Holterhus PM, Piefke S, Hiort O: Anabolic steroids, testosterone-precursors and virilizing androgens induce distinct activation profiles of androgen responsive promoter constructs. J Steroid Biochem Mol Biol 82:269-275 (2002).

-Hoppe U, Holterhus PM, Wünsch L, Jocham D, Drechsler T, et al: Tissue-specific transcription profiles of sex steroid biosynthesis enzymes and the androgen receptor. J Mol Med 84:651-659 (2006).
Hoppe U, Wünsch L, Holterhus PM, Jocham D, Richter-Unruh A, Hiort O: Altered transcription profiles of key-enzymes of androgen biosynthesis in genital skin fibroblasts from patients with 46,XY disorders of sex development (DSD). Sex Dev 1:230-237 (2007).

Kulle AE, Riepe FG, Melchior D, Hiort O, Holterhus PM: A novel ultrapressure liquid chromatography tandem mass spectrometry method for the simultaneous determination of androstenedione, testosterone, and dihydrotestosterone in pediatric blood samples: age- and sex-specific reference data. J Clin Endocrinol Metab 95:2399-2409 (2010).

Labrie F, Luu-The V, Labrie C, Pelletier G, ElAlfy M: Intracrinology and the skin. Horm Res 54:218-229 (2000a).

Labrie F, Luu-The V, Lin SX, Simard J, Labrie C: Role of 17 beta-hydroxysteroid dehydrogenases in sex steroid formation in peripheral intracrine tissues. Trends Endocrinol Metab 11:421-427 (2000b).

Lee YS, Kirk JM, Stanhope RG, Johnston DI, Harland S, et al: Phenotypic variability in 17beta-hydroxysteroid dehydrogenase-3 deficiency and diagnostic pitfalls. Clin Endocrinol (Oxf) 67:20-28 (2007).

Luu-The V: Analysis and characteristics of multiple types of human 17beta-hydroxysteroid dehydrogenase. J Steroid Biochem Mol Biol 76:143-151 (2001).

Luu-The V, Bélanger A, Labrie F: Androgen biosynthetic pathways in the human prostate. Best Pract Res Clin Endocrinol Metab 22: 207-221 (2008).

Martel C, Rheaume E, Takahashi M, Trudel C, Couet J, et al: Distribution of 17 beta-hydroxysteroid dehydrogenase gene expression and activity in rat and human tissues. J Steroid Biochem Mol Biol 41:597-603 (1992).
Moeller G, Adamski J: Integrated view on 17beta-hydroxysteroid dehydrogenases. Mol Cell Endocrinol 301:7-19 (2009).

Nakamura Y, Hornsby PJ, Casson P, Morimoto R, Satoh F, et al: Type 5 17beta-hydroxysteroid dehydrogenase (AKR1C3) contributes to testosterone production in adrenal reticularis. J Clin Endocrinol Metab 94:2192-2198 (2009).

Pelletier G, Luu-The V, Têtu B, Labrie F: Immunocytochemical localization of type $517 \mathrm{be}$ ta-hydroxysteroid dehydrogenase in human reproductive tissues. J Histochem Cytochem 47:731-738 (1999).

Rosler A: 17 beta-hydroxysteroid dehydrogenase 3 deficiency in the Mediterranean population. Pediatr Endocrinol Rev 3 Suppl 3:455461 (2006).

Samson M, Labrie F, Zouboulis CC, Luu-The V: Biosynthesis of dihydrotestosterone by a pathway that does not require testosterone as an intermediate in the SZ95 sebaceous gland cell line. J Invest Dermatol 130:602-604 (2010).

Twesten W, Holterhus P, Sippell WG, Morlot M, Schumacher $\mathrm{H}$, et al: Clinical, endocrine, and molecular genetic findings in patients with 17beta-hydroxysteroid dehydrogenase deficiency. Horm Res 53:26-31 (2000).

-Wudy SA, Hartmann MF: Gas chromatographymass spectrometry profiling of steroids in times of molecular biology. Horm Metab Res 36:415-422 (2004). 